\title{
ERME Column
}

Orly Buchbinder (University of New Hampshire, USA), Jason Cooper (Weizmann Institute of Science, Rehovot, Israel), Gabriel Stylianides (University of Oxford, UK) and Kirsten Pfeiffer (National University of Ireland, Galway)

\section{ERME Topic Conferences}

European Society for Research in Mathematics Education (ERME) Topic Conferences (ETCs) are organised on a specific research theme or themes related to the work of thematic working groups at CERME conferences. Their aim is to extend the work of the group or groups in specific directions, with clear value for the mathematics education research community. Three new ETCs have recently been announced:

- ETC4 on Classroom-based Research on Mathematics and Language, Dresden, Germany, 22-24 March 2018.

- ETC5 on Mathematics Education in the Digital Age (MEDA), Copenhagen, Denmark, 5-7 September 2018.

- ETC6 on University Mathematics Education, Kristiansand, Norway, 5-7 April 2018.

More details can be found on the ERME website (http://www.mathematik.uni-dortmund.de/ erme/index. php?slab=erme-topic-conferences).

\section{ERME Thematic Working Groups}

The European Society for Research in Mathematics Education (ERME) holds a biennial conference (CERME), at which research is presented and discussed in Thematic Working Groups (TWGs). We continue the initiative of introducing the working groups, which we began in the September 2017 issue, focusing on ways in which European research in the field of mathematics education may be interesting or relevant for research mathematicians. Our aim is to extend the ERME community with new participants, who may benefit from hearing about research methods and findings and who may contribute to future CERMEs.

\section{Introducing CERME's Thematic Working Group 1 - Argumentation and Proof \\ Group leaders: Gabriel Stylianides, Orly Buchbinder and Kirsten Pfeiffer}

Thematic Working Group 1 focuses on a topic that is at the very core of mathematics: argumentation and proof. This working group has been represented at CERME from its inception in 1998 and has been growing stronger ever since. At the recent CERME10 conference, which took place in Dublin, Ireland, contributors from 18 countries, across four continents, presented 27 full papers and one poster.

The constantly growing interest in TWG1 reflects the importance that researchers in the field of mathematics education attribute to argumentation and proof for students' learning of mathematics. The papers contributed to this group spanned a wide range of topics and a multitude of methodological approaches. One of the central issues addressed in TWG1 has been the nature of proof and its relationship to argumentation. Participants examined this topic from mathematical, historical, epistemological and theoretical perspectives. These discussions helped bring to the surface both the diversity of positions and their common grounds, and contributed to the emergence of theoretical tools for designing and for researching the teaching and learning of proof.

Another recurring theme of TWG1 has been the complex connection between logic and linguistics in argumentation and proof. Topics in this theme touch upon the value and usefulness of explicit instruction of mathematical logic for fostering proof competencies, such as the writing and the comprehension of proofs. Since logical competence has implications for many advanced mathematical topics, it is critically relevant for both researchers and educators at the tertiary level. Many of the TWG1 papers that examined the relationship between language and logic focused on identifying aspects and situations that are likely to create discontinuities or support between language and logic. The group discussions have been greatly enriched through multi-linguistic and multicultural membership of the group participants, who also brought to the fore the influence of sociocultural contexts on the teaching and learning of proof.

The research reported in TWG1 aims to improve our understanding of argumentation and proof and to enhance its teaching and learning at all levels, from kindergarten to undergraduate - including teacher preparation. Thus, there has been increasing interest among the participants of TWG1 in topics such as the design of curricular materials (e.g. tasks, textbooks and courses) and assessment and classroom intervention studies relating to argumentation and proof. Some of these studies have examined the integration of argumentation and proof into specific subjects such as geometry, (abstract) algebra, calculus and real analysis, while other studies have focused on teaching practices that promote - or inhibit - argumentation and proof in the classroom.

Over the years, the inclusive and collaborative atmosphere of this group has contributed to fruitful research collaborations beyond the CERME meetings, resulting in special issues of international journals, books and other types of scholarship. TWG1 continues to be a rich platform for researchers to present and discuss a plethora of topics on argumentation and proof, which seem to be ever more relevant for the members of the mathematics education community. 


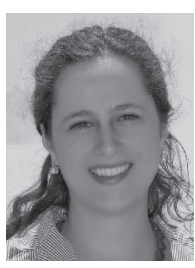

Orly Buchbinder is an assistant professor of mathematics education at the University of New Hampshire, USA. Her research explores teaching and learning of reasoning and proving at the secondary level.

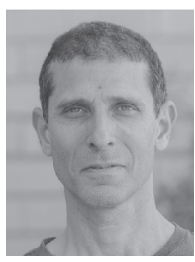

Jason Cooper is a research fellow at the University of Haifa's Faculty of Education. He is also a researcher at the Weizmann Institute's Department of Science Teaching. His research concerns various aspects of teacher knowledge, including roles of advanced mathematical knowledge in teaching and contributions of research mathematicians to the professional development of teachers. He has been a member of the ERME board since 2015.

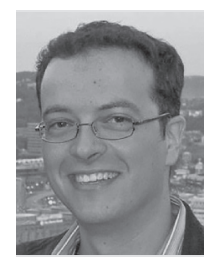

Gabriel Stylianides is a professor of mathematics education at the University of Oxford (UK) and is also a fellow of the University of Oxford's Worcester College. His research focuses on issues related to the meaningful engagement of students at all levels of education (including university students) in fundamental mathematical practices - notably reasoning and proving, problem solving and algebraic thinking.

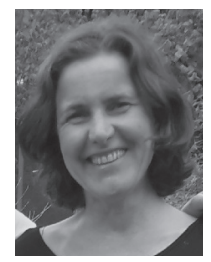

Kirsten Pfeiffer is a lecturer of mathematics and the manager of the mathematics and statistics support centre at the National University of Ireland, Galway. Her research focuses on the teaching and learning of mathematics at university level, with a special interest in the teaching of mathematical proof and the role of mathematics support centres from a sociocultural point of view. 